\title{
O CLIMA EM CIDADE PEQUENA: O SISTEMA TERMODINÂMICO EM JATAÍ (GO)
}

ROCHA, José Ricardo Rodrigues - joserocha90@hotmail.com Universidade Federal de Goiás, Regional Jataí - Jataí (GO) - Brasil

MARIANO, Zilda de Fátima - zildadefatimamariano@gmail.com Universidade Federal de Goiás, Regional Jataí - Jataí (GO) - Brasil.

FELTRIN, Jean Carlos

Universidade Federal de Goiás, Regional Jataí - Jataí (GO) - Brasil.

SILVA, Márcio Rodrigues da - marcioufg@gmail.com

Universidade Federal de Goiás, Regional Jataí - Jataí (GO) - Brasil.

RESUMO: O crescimento e a falta de infraestrutura das cidades vêm ocasionando inúmeros impactos negativos para a qualidade do meio urbano, visto que estas áreas são capazes de provocar impactos sobre o clima local, contribuindo de forma negativa ou positiva para a qualidade de vida da população. As transformações que ocorrem no meio natural acabam provocando mudanças, que, por consequência, influenciam os elementos climáticos, ocasionando as ilhas de calor, ou seja, locais que apresentam as maiores temperaturas em áreas urbanizadas em relação às áreas rurais. O objetivo do trabalho foi a análise e comparação das características da temperatura do ar e do conforto térmico na cidade de Jataí, buscando investigar prováveis diferenças nos elementos do clima em condições adversas de uso e ocupação do solo, por meio da abordagem sistêmica do clima urbano (S.C.U), proposta por Monteiro (1976), utilizando o canal termodinâmico. Diante dos resultados, verificou-se que a temperatura efetiva (sensação térmica) das 9 horas ficou entre a zona de conforto térmico, com exceção na estação do inverno, com desconforto ao frio. Já no horário das 15 horas, todos os meses apresentaram desconforto térmico ao calor, exceto os dias 30 de maio e 08 de junho, com desconforto ao frio. No horário das 21 horas, as temperaturas prevaleceram na zona de conforto nas localidades, tanto na mais urbanizada quanto na menos urbanizada.

Palavras chave: Clima, conforto térmico, termodinâmico, Jataí-GO.

THE CLIMATE IN SMALL TOWN: THE THERMODYNAMIC SYSTEM IN JATAÍ (GO) $A B S T R A C T:$ The growth and the lack of infrastructure of the cities are causing countless negative impacts on the quality of the urban environment, as these areas are capable of causing impacts on local climate, contributing negatively or positively to the population's life quality. The transformations that occur in the natural environment end up causing changes, which consequently influence the climatic elements, causing the heat islands, that is, places that have the highest temperatures in urban areas compared to rural ones. The aim of this paper was to analyze and compare the characteristics of the air temperature and the thermal comfort in the city of Jataí in order to investigate possible differences in the elements of the climate in adverse use conditions and land occupation, through the systems approach to the urban climate (S. A. U. C) proposed by Miller (1976) using the thermodynamic channel. Facing the results, it was found 
that the effective temperature (wind chill) from 9 am was in the midst of the thermal comfort zone, except in the winter, with uneasy feelings while chilling. However, at 3 pm, every month depicted thermal heat discomfort except on May $30^{\text {th }}$ and June $8^{\text {th }}$, with uneasy feelings while chilling. At $9 \mathrm{pm}$, temperatures prevailed in the comfort zone in the localities both urbanized and less urbanized.

Keywords: Climate, thermal comfort, thermodynamic, Jataí-GO.

\section{INTRODUÇÃO}

O homem vem provocando alterações no clima urbano por meio das transformações da natureza na ocupação e modelação do espaço. Hoje, o crescimento desordenado das cidades e as formas de ocupações do solo urbano, aliados à falta de infraestrutura, vêm ocasionando inúmeros impactos negativos para a qualidade do meio urbano. Barbosa e Amorim (2012) apontaram que, por meio do processo de urbanização, as cidades constituíram-se no desenvolvimento das relações humanas. Nas cidades brasileiras, a partir da década de 1950, verificou-se um crescimento mais intenso, aumentando o número de pessoas que nelas passaram a viver.

Este aumento, ocasionado pela intensa urbanização nos últimos anos, acarretou diversos danos à sociedade, como colocam Lima e Zanela (2011, p. 1):

[...] devido à rápida e desordenada urbanização que vem ocorrendo nas cidades brasileiras desde meados do século XIX, foi gerada uma degradação ambiental mais intensa e uma queda da qualidade de vida da população. Logo, a ação do homem e os processos decorrentes de sua organização social têm gerado alterações no meio ambiente, em especial no meio urbano.

Assim, durante o processo de urbanização ocorre a substituição do ecossistema natural por outro completamente adverso, buscando atender às necessidades do ser humano. Anunciação e Sant'Anna Neto (2002, p. 62) colocam que "o espaço urbano é o maior palco das ações impactantes, da organização da superfície terrestre e da deterioração do ambiente".

De acordo com Basane (2011), com esta intensa urbanização, ocorre a impermeabilização do solo, ocasionando a diminuição da evaporação, a evapotranspiração e a infiltração, gerando desconforto térmico. Assim, essas transformações que ocorrem acabam provocando grandes mudanças nas características do meio, que, por consequência, 
influenciam os elementos climáticos em escala local, gerando assim as ilhas de calor, ou seja, locais que apresentam as maiores temperaturas em áreas urbanizadas em relação às áreas rurais.

Desta forma, o padrão de ocupação do solo influenciará as condições climáticas locais, como coloca Lombardo (1985, p. 77):

[...] as condições climáticas de uma área urbana extensa e de construção densa são totalmente distintas daquelas dos espaços abertos circundantes, podendo haver diferenças de temperaturas, de velocidade do vento, de umidade, de pureza do ar etc.

Para Fialho e Souza (2007, p.30), "dentre as categorias frequentemente utilizadas pela Geografia, o clima toma importante valor pelo seu potencial de relação com diversos processos, nos quais as aglomerações urbanas imprimem uma nova conotação".

Para Basane (2011, p. 2),

a urbanização gera o aumento tanto horizontal quanto vertical das estruturas urbanas, tendo acréscimo significativo no coeficiente de rugosidade na superfície, alterando o deslocamento do vento, temperatura do ar, infiltração da água e a evaporação no interior da cidade.

Segundo Oke (1978), o clima urbano pode ser definido como o resultado das modificações causadas pelo processo de urbanização da superfície terrestre e da interferência dessa urbanização nas características da atmosfera de um determinado local.

Os primeiros estudos sobre a temática do clima urbano abordam geralmente as cidades de grande porte, pois a magnitude dos problemas urbanos causados é mais evidenciada. Por outro lado, as cidades pequenas também estão ganhando destaque devido ao aumento das temperaturas (ilha de calor), enchentes causadas pela forma do uso do solo urbano e pelo adensamento de pessoas passando a viver nessas cidades.

Para Rossato (2010), o estudo do clima urbano das pequenas cidades torna-se interessante também pelo fato de se poder estabelecer comparações com estudos feitos em cidades maiores, a fim de relacionar o grau de influência dos espaços urbanos com diferentes dimensões no clima de cada local.

Desta forma, toda modificação gerada no ambiente acaba por 
modificar o clima local; assim, esse clima acaba por influenciar a qualidade de vida da população, como por exemplo, o conforto térmico, apontado por Amorim (2010, p. 72):

práticas como a impermeabilização dos solos, a utilização de materiais construtivos inadequados, a retirada da cobertura vegetal original, a canalização fechada de rios e córregos, a emissão de poluentes para a atmosfera têm sido frequentes nas cidades. Essas modificações, associadas às características naturais dos ambientes tropicais, têm proporcionado a geração de ilhas de calor e têm sido registradas situações de desconforto térmico na maioria das cidades onde os estudos têm sido realizados.

De acordo com Andrade (2005), a qualidade de vida é um conceito central no planejamento urbano, sendo que o clima urbano deve ser considerado enquanto componente de qualidade do ambiente e, portanto, de contribuição para a qualidade de vida no meio urbano. Ainda enfatiza que o clima urbano pode afetar diretamente a saúde e bem-estar humano, sendo possível distinguir, nessa influência, diferentes fatores, entre ele o conforto térmico.

Mendonça (2001, p.49) coloca que a saúde humana é influenciada pelo clima, e que esses efeitos na população são mais acentuados às pessoas que estão à mercê de sua ação:

\begin{abstract}
Quando os fatores do ambiente atingem valores extremos, sob atuação de ondas de calor ou frio, de ventos violentos, ou de precipitações abundantes, por exemplo, então eles afetam a saúde humana. Assim, a mortalidade aumenta durante as ondas de calor (sobretudo crianças e idosos), sendo cada vez mais marcada quando temperaturas elevadas se combinam com forte higrometria.
\end{abstract}

Desta forma, diversos estudos vêm sendo desenvolvidos para verificar a qualidade ambiental em função da temperatura efetiva (sensação térmica), como o estudo desenvolvido por Barduco e Galvani (2013), que ao investigarem as situações de conforto térmico em transporte público, verificaram que há condições de conforto em momentos que a lotação do ônibus foi inferior a 20 passageiros, o que evidencia que a quantidade de passageiros tem influência direta na condição de conforto térmico do ônibus.

Percebe-se que a importância do conforto térmico não se relaciona apenas à sensação de conforto, mas também ao seu 
desempenho, tanto no trabalho, no modo de vida da população e na saúde das pessoas. De acordo com a Organização Mundial de Saúde (2012), o calor excessivo é uma ameaça crescente de saúde pública. Para cada grau centígrado, as mortes podem aumentar em 2 a $5 \%$. 0 calor intenso aumenta os riscos à saúde dos idosos e portadores de doenças crônicas, indivíduos socialmente isolados, pessoas que trabalham em exposição a ambientes e crianças são particularmente vulneráveis.

Assim, parte-se do pressuposto que a modificação e intensificação urbana em Jataí geram diferentes microclimas dentro da cidade, pois o estudo de Silva (2005) coloca que, a partir da década de 1970, começaram as mudanças na estrutura do uso do solo da cidade de Jataí; assim, essa mudança da estrutura pode contribuir para a modificação do clima local. Desta forma, o objetivo do trabalho foi analisar e comparar a temperatura do ar e o conforto térmico na cidade de Jataí, em condições diferentes de uso e ocupação do solo.

\section{PROCEDIMENTOS METODOLÓGICOS}

O trabalho propôs um estudo do clima urbano em uma cidade de pequeno porte do cerrado, Jataí, localizada na microrregião do sudoeste do estado de Goiás (Figura 1). Jataí é considerada uma cidade de pequeno porte, visto que o $\operatorname{ABDALA}(2013$, p. 01) coloca que são consideradas "pequenas as cidades com até 100 mil habitantes, médias as cidades com população compreendida entre 100 e 500 mil habitantes e, com população acima de 500 mil habitantes, cidades de grande porte" apontado por Santos, Costa e Andrade (2001), e, de acordo com IBGE (2010), Jataí possui 88.006 habitantes. 


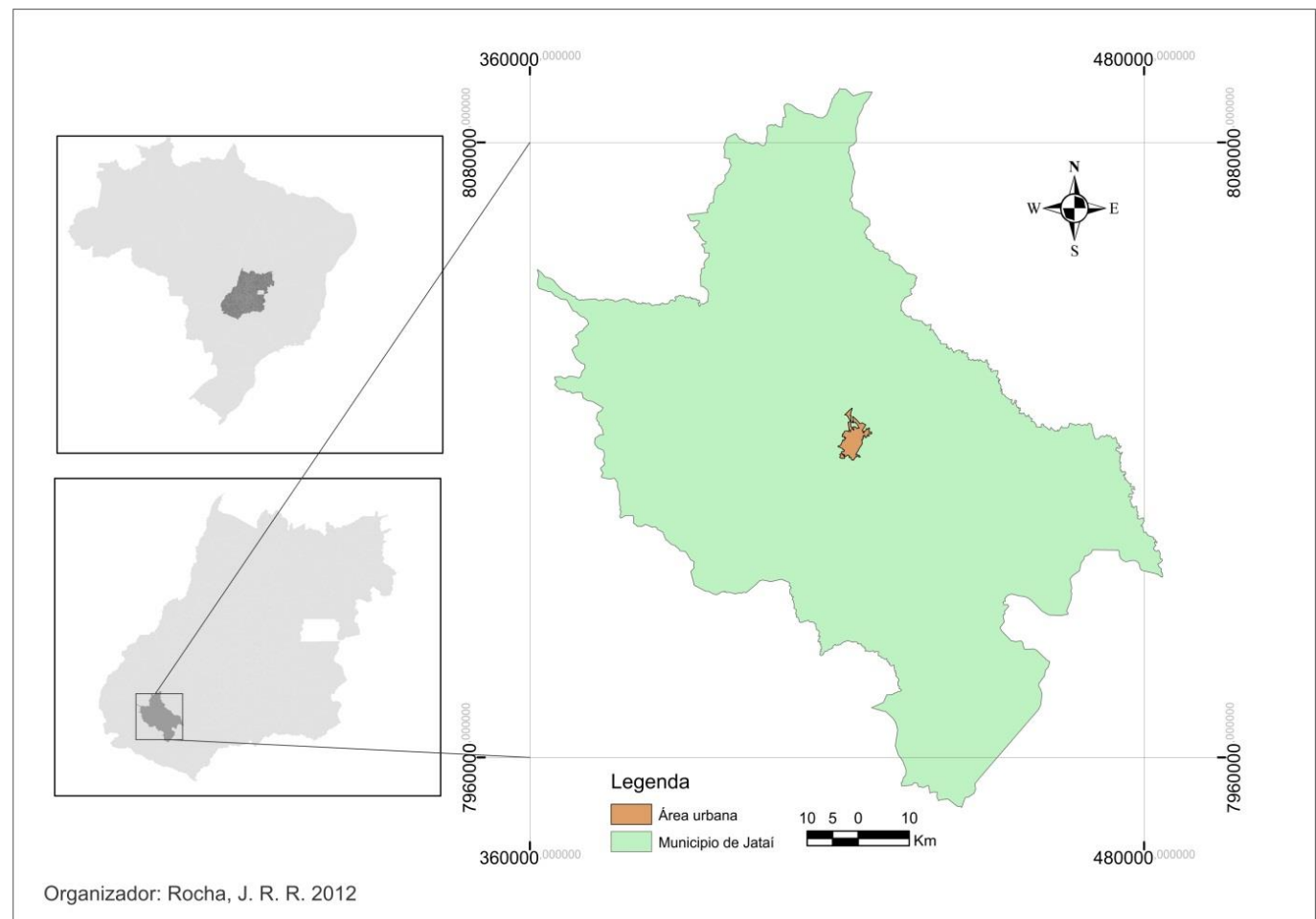

Figura 1: Localização da cidade de Jataí - GO / Fonte: Rocha, J. R. R. 2012

Para a coleta de dados de temperatura e umidade relativa do ar foram utilizados termohigrômetros (Datalogger, modelo HT-500). Os termohigrômetros foram instalados em diversos pontos na área urbana de Jataí, em miniabrigos de madeira com altura de 1,50 m do solo, pintados na cor branca e revestidos com telas de nylon para proteção contra os insetos (Figura 2, A e B).

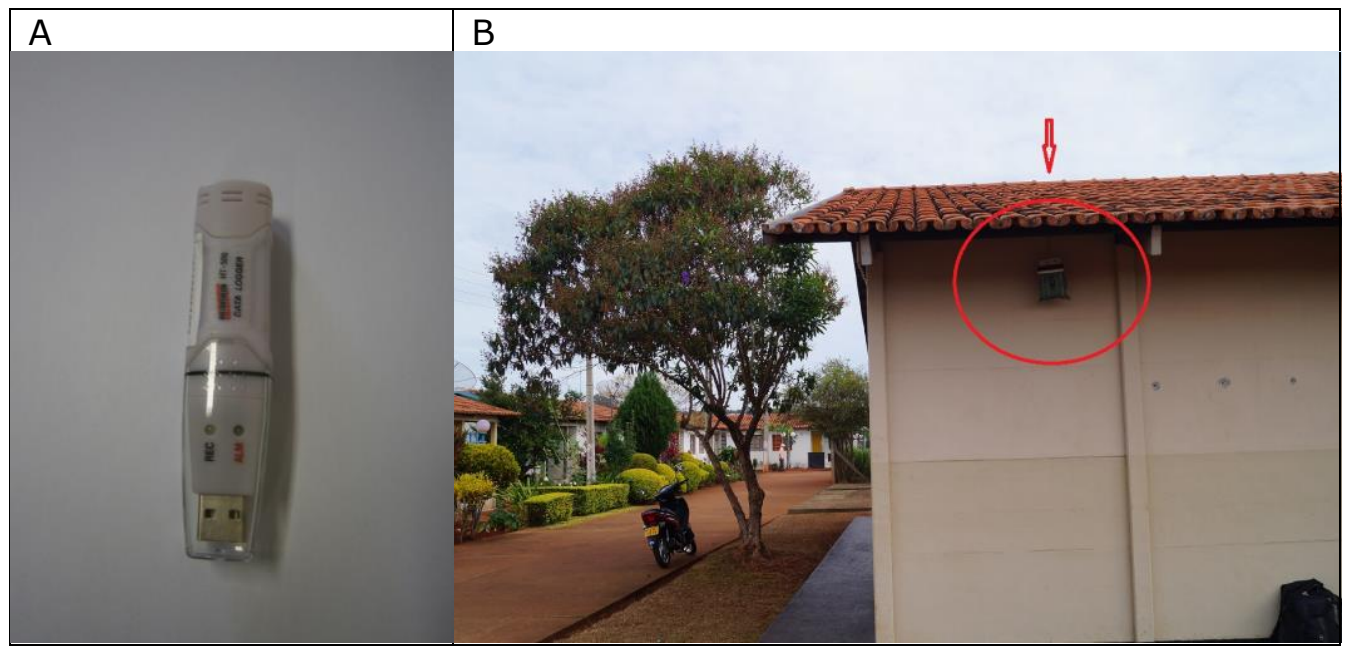

Figura 2: A) Datalogger HT - 500 B) Abrigo com o Datalogger (instalado, P8) / Fonte: Rocha, J. R. R. 2012 
A base metodológica utilizada foi a Teoria do Clima Urbano (S.C.U), baseada no canal termodinâmico ligado com o meio natural ou construído, o qual influencia diretamente no conforto térmico do indivíduo, preconizado por Monteiro (1976). Assim, o estudo desenvolve-se partir das características da temperatura e umidade relativa do ar e o cálculo do conforto térmico.

Para análise da temperatura do ar, os valores máximos e mínimos absolutos, no período de janeiro a dezembro de 2012, foram coletados nos pontos Bairro Mauro Bento (P1), Centro Técnico Sucam (P2), Unidade Riachuelo (P3), Centro Sucam (P4), Clube dos Sargentos (P5), Clube dos Militares (P6), Estação do INMET (P7) e Vila Vida (P8) (Figura 3).

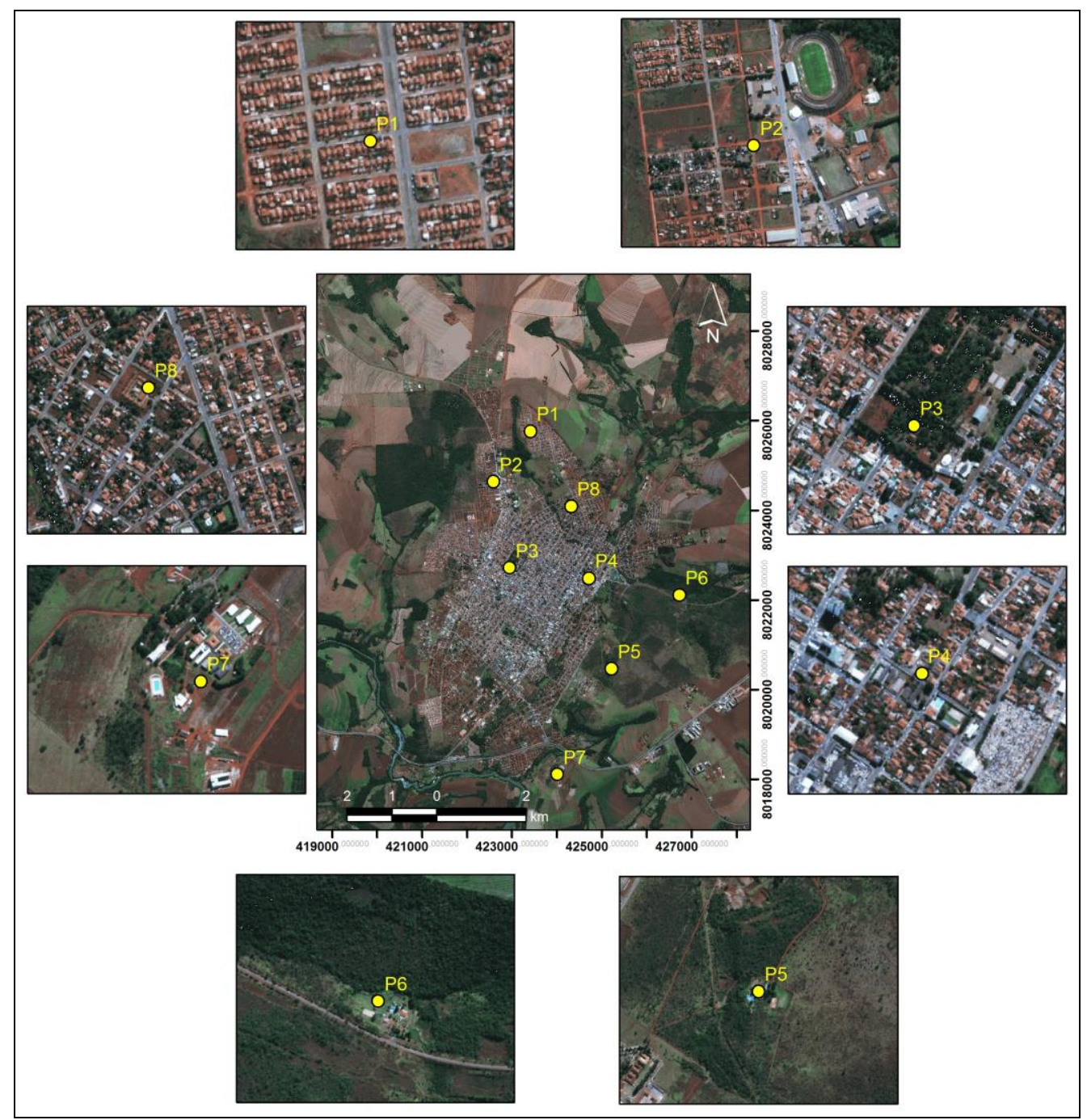

Figura 3 - Localização dos pontos de coleta na cidade de Jataí-GO / Organização: ROCHA, J. R. R. (2013)

Os cálculos diários de Temperatura Efetiva (TE) foram realizados às 
9, 15 e 21 horas. A temperatura efetiva foi obtida por meio de equações (Equações 01, 02, 03, 04 e 05, elaboradas por Thom (1959) e utilizadas nos estudos de Vicente et al (2002) e Silva e Amorim (2010) (Equação 1).

$T E=0,4(T s+T u)+4,8$

Onde:

TE - Temperatura efetiva;

Ts - Temperatura de bulbo seco;

Tu - Temperatura de bulbo úmido.

De acordo com Vicente et al (2002), o cálculo do índice térmico é o mais aceito entre os pesquisadores e o mais simples para a determinação do conforto térmico. Neste cálculo, temperaturas entre 18,9 a $25,6^{\circ} \mathrm{C}$ representam conforto, enquanto que temperaturas acima de $25,6{ }^{\circ} \mathrm{C}$ são configuradas como stress pelo calor (desconforto para o calor) e abaixo de $18,9^{\circ} \mathrm{C}$ é condição de stress pelo frio (desconforto para o frio).

Antes de efetuar o cálculo da temperatura efetiva, fez-se necessário transformar a temperatura instantânea do ar em valor de temperatura de bulbo úmido. Para a conversão, utilizou-se o método de Pereira et al (2004), por meio das equações 2 (Cálculo da pressão de saturação (es) em kPa; 3 (Pressão de vapor do ambiente (e), em kPa; 4 e 5 (variáveis g e d) e 6 (Cálculo da temperatura de bulbo úmido (Tu) em ${ }^{\circ} \mathrm{C}$ ).

$$
\text { es }=0,611 * \operatorname{EXP}(17,27 * T /(T+237,3)
$$

onde:

es = pressão de saturação $(\mathrm{kPa})$;

$\mathrm{T}=$ temperatura do ar (Bulbo seco)

onde:

$$
\mathrm{e}=(\mathrm{es} * \mathrm{UR}) / 100
$$

$\mathrm{e}=$ Pressão de vapor do ambiente $(\mathrm{kPa})$

es $=$ pressão de saturação $(\mathrm{kPa})$

$\mathrm{UR}=$ Umidade relativa do $\operatorname{ar}(\%)$

$$
g=0,00066 \times P
$$

onde:

$g=$ variável

$\mathrm{P}=$ é a pressão barométrica ambiente em $\mathrm{kPa}$,

$$
d=4098 * e /(\text { To }+237,3)^{2}
$$

onde:

d=Variável 
$\mathrm{e}=$ Pressão de vapor do ambiente $(\mathrm{kPa})$

$\mathrm{To}=$ Temperatura de orvalho $\left({ }^{\circ} \mathrm{C}\right)$

$$
\mathrm{Tu}=[(\mathrm{g} * \mathrm{~T})+(\mathrm{d} * \mathrm{To})] /(\mathrm{g}+\mathrm{d})
$$

onde:

$\mathrm{Tu}=$ Temperatura do bulbo úmido $\left({ }^{\circ} \mathrm{C}\right)$

$\mathrm{g}=$ Variável

$\mathrm{T}=$ Temperatura do Bulbo seco $\left({ }^{\circ} \mathrm{C}\right)$

$\mathrm{d}=$ Variável

To $=$ Temperatura de Ponto de Orvalho $\left({ }^{\circ} \mathrm{C}\right)$

Para realizar a comparação do Índice de Temperatura Efetiva, foram relacionados dois padrões de ocupação de urbanização diferenciados, sendo o P2 (Centro Tecnológico Sucam), no setor Epaminondas, a noroeste da cidade, com pouca pavimentação asfáltica, terrenos vagos, arborização e pouco fluxo de veículos e pessoas, e a localidade P6 (Centro Sucam), situada paralelamente à avenida principal da cidade (Av. Goiás), com intenso fluxo de veículos e pessoas, casas comerciais, arborização nos fundos dos quintais, total pavimentação asfáltica, pois é o centro comercial da cidade.

Também foram analisados os sistemas atmosféricos atuantes nos dias selecionados, por meio das imagens do satélite Goes 13.

\section{RESULTADOS E DISCUSSÃo}

3.1 variação das temperaturas do ar máxima e miníma absoluta em jataí no ano de 2012

Verificamos que, no período de janeiro a dezembro de 2012, as temperaturas máximas absolutas oscilaram entre $31,3^{\circ} \mathrm{C}(\mathrm{P} 2)$ em julho e $45,6^{\circ} \mathrm{C}$ (P1) em outubro. As localidades $\mathrm{P} 4$ e $\mathrm{P} 1$, devido suas características, apresentaram as maiores temperaturas máximas absolutas, pois o P4 situa-se no centro da cidade (totalmente pavimentado, fluxo de veículos e pessoas, arborização nos fundos dos quintais) e o P1 no Conjunto Residencial Mauro Antônio Bento (conjunto habitacional com casas próximas, pouca arborização e totalmente pavimentado), características que contribuíram para o aquecimento.

Nos meses de janeiro e fevereiro, as temperaturas máximas absolutas ocorreram no P4 $\left(41,8\right.$ e $41,4^{\circ} \mathrm{C}$, respectivamente); em março, no P3, com $39,8^{\circ} \mathrm{C}$; de abril a agosto, ocorreram na localidade P1 (40,0; 38,$4 ; 37,6 ; 40,2$ e $40,0^{\circ} \mathrm{C}$, respectivamente); em setembro, a maior 
temperatura máxima absoluta ocorreu no P3 $\left(44,6^{\circ} \mathrm{C}\right)$; em outubro, no P1 $\left(45,6^{\circ} \mathrm{C}\right)$; e, em novembro e dezembro, no P4 $\left(44,1\right.$ e $\left.43,1^{\circ} \mathrm{C}\right)$.

Em relação às menores temperaturas máximas absolutas, verificou-se que os menores valores foram encontrados no P7 e P2, em que a localização influenciou os valores, considerando que o P7 está situado em área rural (UFG-Estação do INMET) e o P2 conta com pouca construção de casas, pavimentação e arborização.

Desta forma, de janeiro a maio, as menores temperaturas máximas ocorreram na localidade $\mathrm{P} 7\left(32,7 ; 34,9 ; 33,5 ; 33,4\right.$ e $31,6{ }^{\circ} \mathrm{C}$, respectivamente); nos meses de julho, outubro e dezembro $(33,1 ; 39,0$ e $34,5^{\circ} \mathrm{C}$, respectivamente); nos meses de junho, agosto, setembro e novembro ocorreram no P2 $\left(31,3 ; 32,4 ; 37,7\right.$ e $33,9{ }^{\circ} \mathrm{C}$, respectivamente) (Figura 4).

A partir do mês de maio, verificamos que as temperaturas máximas absolutas começaram a diminuir, sendo que Silva e Andrade (2010, p. 4) colocam que a região possui "seis meses de inverno seco e ameno, que compreendem os meses de Abril a Setembro". Assim, percebemos que as características contribuíram para que ocorressem essas menores temperaturas, tanto nas máximas quanto nas mínimas absolutas. 


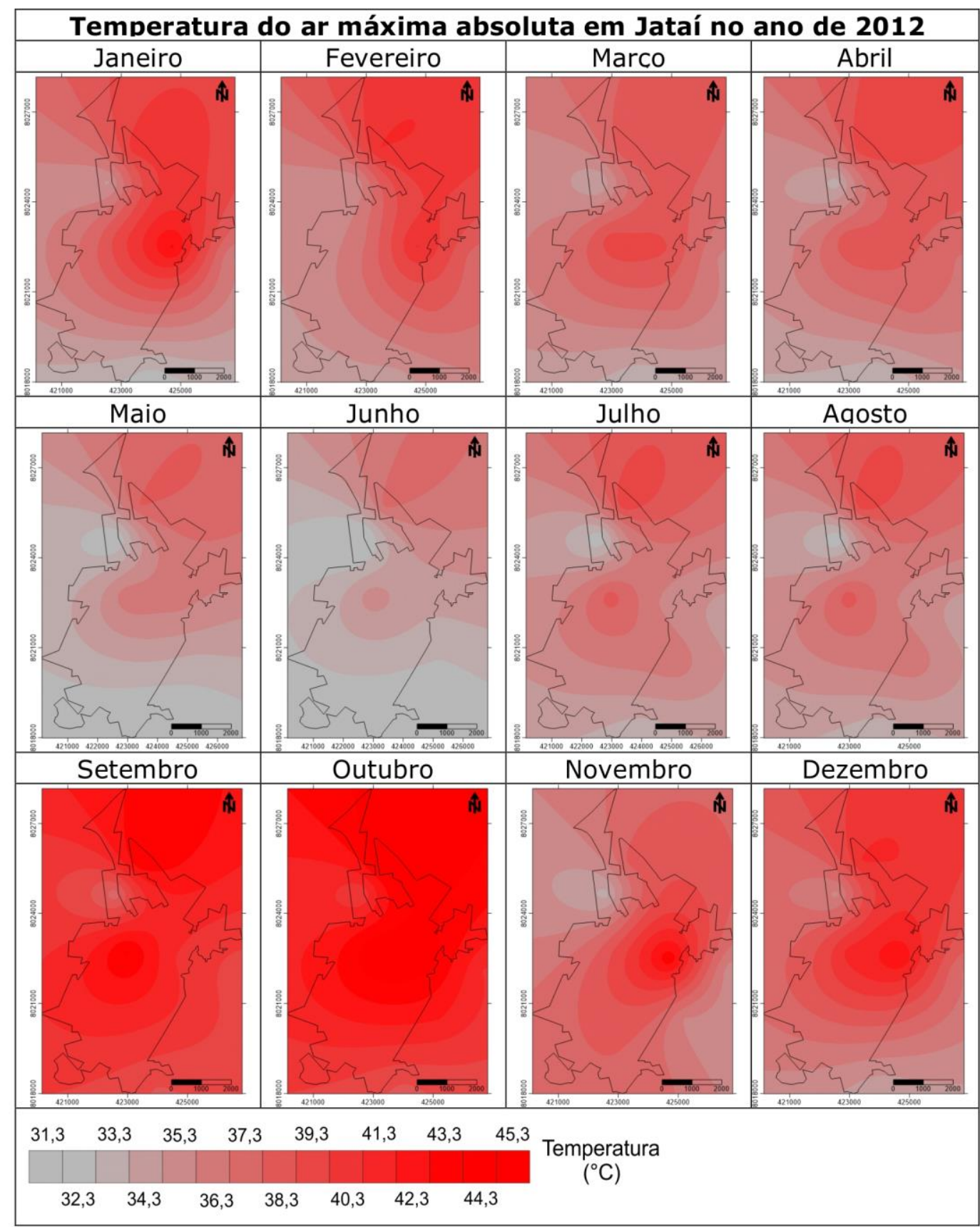

Figura 4 - Variação da temperatura do ar máxima absoluta em Jataí (2012) / Fonte: Laboratório de Climatologia. UFG/Regional Jataí / Elaboração: ROCHA, J. R. R (2013)

Em relação à temperatura mínima absoluta na malha urbana de Jataí, no ano de 2012, verificamos que as maiores temperaturas mínimas ocorreram no mês de dezembro, em quase todos os pontos, exceto no P2, que ocorreu em novembro. Assim, os pontos apresentaram as seguintes temperaturas: o $\mathrm{P} 1\left(19,1^{\circ} \mathrm{C}\right), \mathrm{P} 2\left(19,9^{\circ} \mathrm{C}\right), \mathrm{P} 3\left(17,7^{\circ} \mathrm{C}\right), \mathrm{P} 4\left(20,0^{\circ} \mathrm{C}\right), \mathrm{P} 5$ 
$\left(19,3^{\circ} \mathrm{C}\right) \mathrm{P} 6\left(18,1^{\circ} \mathrm{C}\right), \mathrm{P} 7\left(8,0^{\circ} \mathrm{C}\right)$ e P8 $\left(19,7^{\circ} \mathrm{C}\right)$. No decorrer do ano, de fevereiro a novembro, a localidade $\mathrm{P} 2$ foi a que obteve temperaturas mínimas absolutas maiores $(19,2 ; 18,0 ; 13,3 ; 10,5 ; 12,9 ; 8,0 ; 15,9$; 12,$7 ; 19,9^{\circ} \mathrm{C}$, respectivamente), com exceção em janeiro e dezembro, na localidade P4 $\left(19,3\right.$ e $\left.20,0^{\circ} \mathrm{C}\right)$. Desta forma, percebe-se que o P2 teve as maiores temperaturas mínimas absolutas, exceto em janeiro e dezembro, que foram registradas na localidade $\mathrm{P} 4$.

Já as menores temperaturas mínimas apresentaram no mês de julho, sendo o P1 $\left(6,4^{\circ} \mathrm{C}\right), \mathrm{P} 2\left(8,0^{\circ} \mathrm{C}\right), \mathrm{P} 3(3,8), \mathrm{P} 4\left(4,7^{\circ} \mathrm{C}\right), \mathrm{P} 5\left(4,5^{\circ} \mathrm{C}\right)$ $\mathrm{P} 6\left(1,7^{\circ} \mathrm{C}\right), \mathrm{P} 7\left(1,9^{\circ} \mathrm{C}\right)$ e $\mathrm{P} 8\left(5,8^{\circ} \mathrm{C}\right)$. Entre os pontos, verificamos que a localidade P6 foi onde ocorreram as menores temperaturas mínimas absolutas nos meses de janeiro a março $\left(16,6 ; 16,3\right.$ e $15,7{ }^{\circ} \mathrm{C}$, respectivamente), maio a novembro $(7,4 ; 8,4 ; 1,7 ; 9,7 ; 8,8 ; 15,0$ e 15,9 ${ }^{\circ} \mathrm{C}$, respectivamente), sendo nos meses de abril $\left(12,1^{\circ} \mathrm{C}\right)$ e dezembro $\left(17,7^{\circ} \mathrm{C}\right)$ na localidade $\mathrm{P} 3$. 


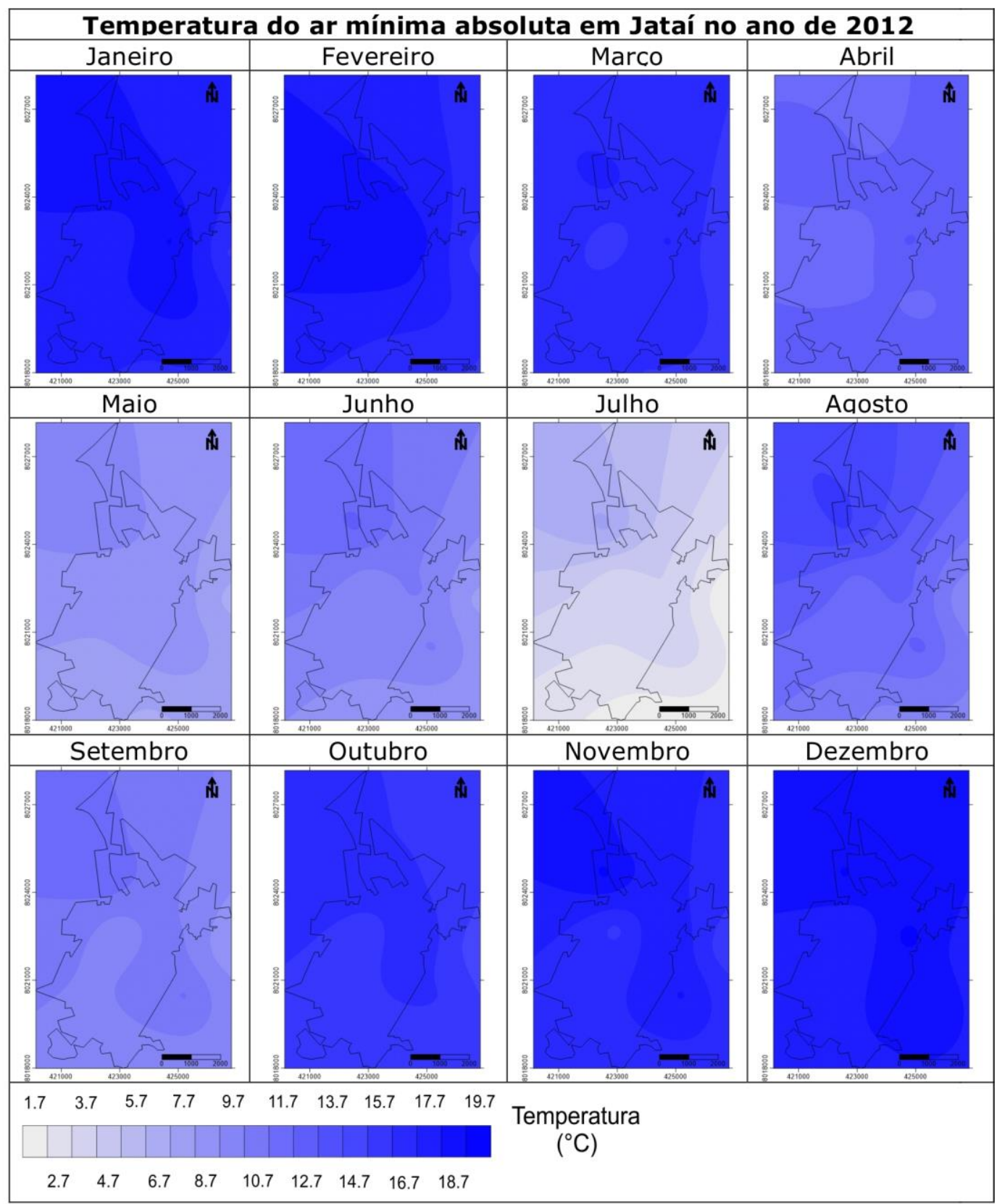

Figura 5 - Variação da temperatura do ar mínima absoluta em Jataí (2012) / Fonte: Laboratório de Climatologia. UFG/Regional Jataí / Elaboração: ROCHA, J. R. R (2013)

Pode-se perceber que as maiores temperaturas máximas absolutas foram encontradas na localidade P4, devido à sua localização paralela à avenida principal da cidade (Av. Goiás), com intenso fluxo de veículos, pessoas, centro comercial e agências bancárias e próximo da área industrial, com barracões (telhado de zinco) e as temperaturas mínimas no P2, devido a terrenos vagos, arborização, pouca pavimentação e fluxo de pessoas (Mapa 2). 
Desta forma, a temperatura máxima absoluta oscilou entre 31,3 a $45,6^{\circ} \mathrm{C}$, com a maior amplitude de $10,2^{\circ} \mathrm{C}$ entre os pontos em novembro e, nos meses de março e junho, a menor amplitude, com $6,3^{\circ} \mathrm{C}$. No mês com maior amplitude térmica (novembro), o ponto $\mathrm{P} 4$ teve a maior temperatura máxima absoluta, $45,6^{\circ} \mathrm{C}$, e o ponto com menor temperatura máxima absoluta foi o $\mathrm{P} 2$, com $31,6^{\circ} \mathrm{C}$ (Quadro 1 ).

A temperatura mínima absoluta variou entre 1,7 a $8,0^{\circ} \mathrm{C}$, com maior amplitude em julho $\left(6,3^{\circ} \mathrm{C}\right)$, em que a localidade $\mathrm{P} 2$ teve a maior temperatura mínima absoluta, com $8,0^{\circ} \mathrm{C}$, e a localidade $\mathrm{P} 6 \mathrm{com}$ a menor temperatura mínima absoluta $\left(1,7^{\circ} \mathrm{C}\right)$ e a menor amplitude ocorreu em abril, com $1,7^{\circ} \mathrm{C}$ (Quadro 1 ).

Tabela 1 - Amplitude térmica em Jataí (GO), 2012, entre os pontos (P1 a P8)

\begin{tabular}{ccccccccccccccc}
\hline $\begin{array}{c}\text { Amplitude } \\
\text { absoluta }\left({ }^{\circ} \mathrm{C}\right)\end{array}$ & Jan & Fev & Mar & Abr & Mai & Jun & Jul & Ago & Set & Out & Nov & Dez \\
\hline $\begin{array}{c}\text { Temperatura } \\
\text { máxima }\end{array}$ & 9,1 & 6,5 & 6,3 & 6,6 & 6,8 & 6,3 & 7,1 & 7,6 & 6,9 & 6,6 & 10,2 & 8,6 \\
$\begin{array}{c}\text { Temperatura } \\
\text { mínima }\end{array}$ & 3,2 & 3,1 & 2,3 & 1,7 & 3,1 & 4,5 & 6,3 & 6,2 & 3,9 & 2,7 & 4 & 2,3 \\
\hline
\end{tabular}

Fonte: Laboratório de Climatologia. UFG/Regional Jataí

Elaboração: ROCHA, J. R. R (2013)

\subsection{O conforto térmico em áreas com densidades de urbanização diferentes}

Diante dos resultados das temperaturas máximas e mínimas absolutas, nos oitos pontos da cidade, com padrões de urbanização diferenciados, foram selecionadas as localidades P4, no centro da cidade, com intenso fluxo de veículos e pessoas, devido à proximidade com a área comercial e a localidade P2, pois é bairro residencial, com pouca pavimentação, terrenos vagos e arborizações (Figura 6) 

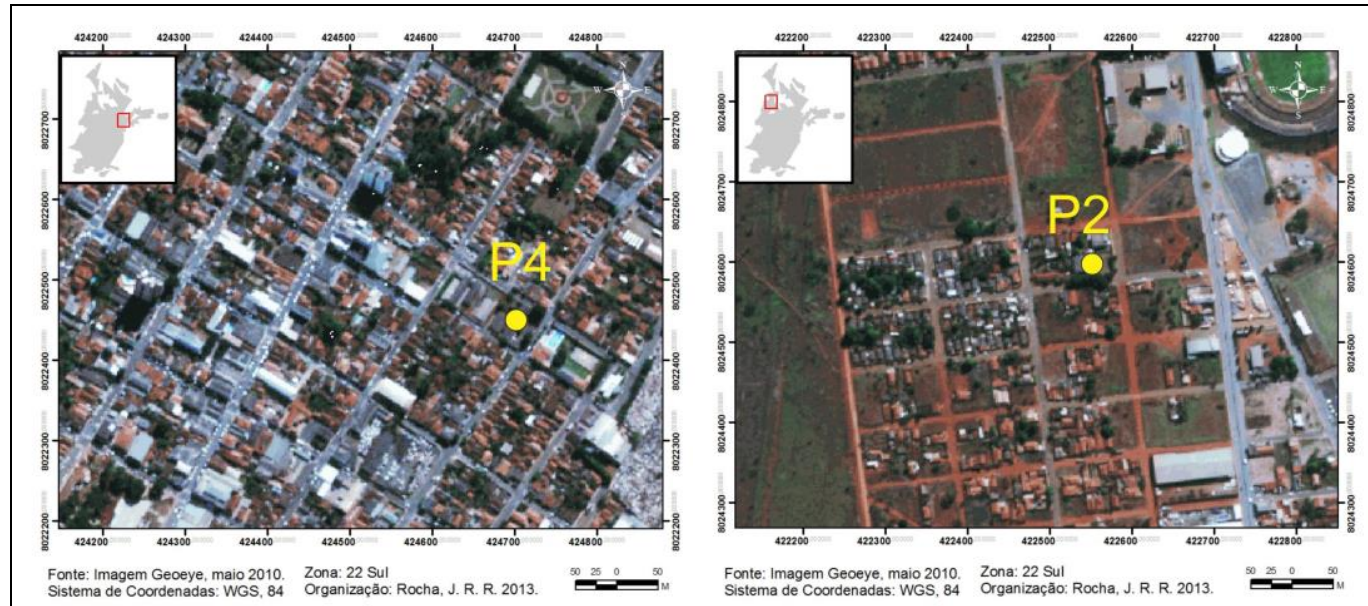

ra 6 - Localização do P4 e do P2 em Jataí (GO) / Organização: ROCHA, J. R. R. 2013

\subsection{1 - Temperatura efetiva às 9 horas}

As temperaturas efetivas às 9 horas, na localidade P4 (área mais urbanizada), oscilaram de 29,2 a $12,2^{\circ} \mathrm{C}$, com amplitude térmica de $17,0^{\circ} \mathrm{C}$, em que a maior temperatura efetiva ocorreu em dezembro (dia 25), com $29,2^{\circ} \mathrm{C}$ e a menor em julho (dia 19), com $12,2{ }^{\circ} \mathrm{C}$.

O conforto térmico $\left(18,9\right.$ a $\left.25,6^{\circ} \mathrm{C}\right)$ ocorreu em 229 dias e alguns dias na estação do inverno (maio, junho e julho); as temperaturas apresentaram-se desconfortáveis em relação ao frio (abaixo de $18,9^{\circ} \mathrm{C}$ ), devido à atuação da massa polar que adentrou a região, trazendo consigo a frente fria, ocasionando a diminuição das temperaturas na região, com 39 dias com desconforto em relação ao frio. Já nos meses de outubro, novembro, dezembro, fevereiro, março e abril, ocorreram dias com temperaturas efetivas desconfortáveis ao calor (acima de 25,6 ${ }^{\circ} \mathrm{C}$ ), com 97 dias (Figura 7).

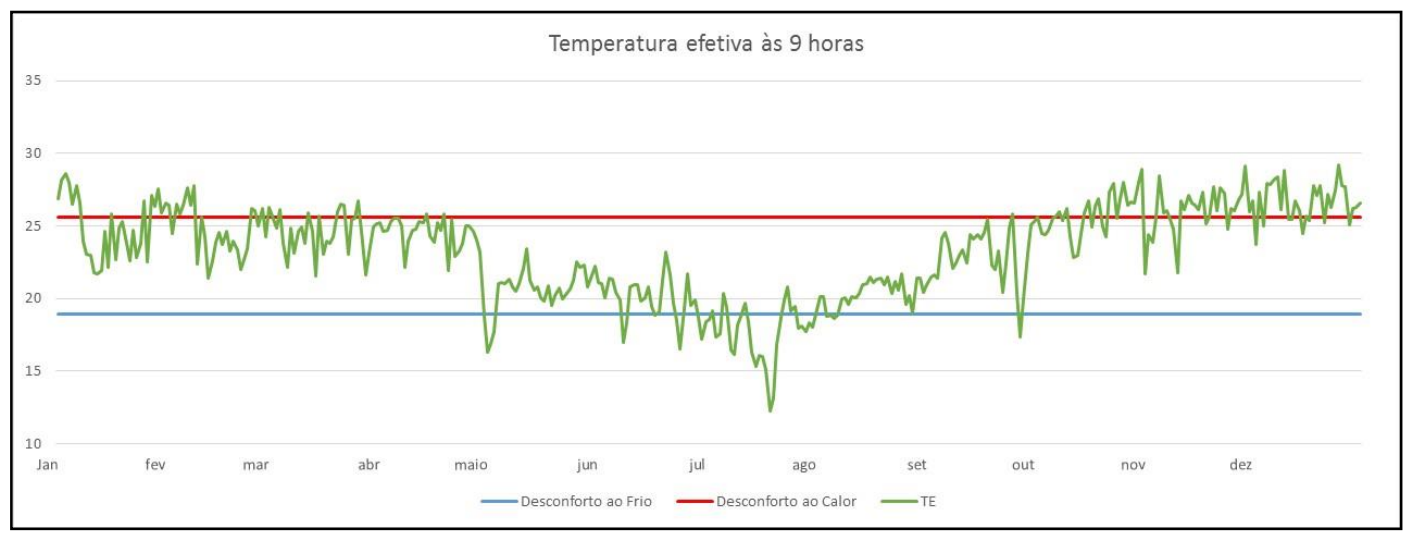


Figura 7 - Temperatura efetiva em área mais urbanizada (P4) às 9 horas / Fonte: Laboratório de Climatologia. UFG/Regional Jataí / Organização: ROCHA, J. R. R (2013)

Na localidade P2 (área menos urbanizada), a temperatura efetiva oscilou entre 13,6 a $26,9^{\circ} \mathrm{C}$, com amplitude de $13,3^{\circ} \mathrm{C}$, sendo que a maior temperatura efetiva foi de $26,9^{\circ} \mathrm{C}$, no mês de outubro (dia 30), assim caracterizando como desconforto térmico para o calor, com 12 dias, devido aos terrenos largos, ruas não pavimentadas totalmente e índice alto de arborização, proporcionando qualidade ambiental para a população residente. Em relação ao desconforto ao frio, a menor temperatura efetiva foi de $13,6^{\circ} \mathrm{C}$, em 17 de julho. Desta forma pode-se perceber uma tendência no inverno às temperaturas efetivas menores, gerando desconforto para o frio, totalizando 20 dias (Figura 8).

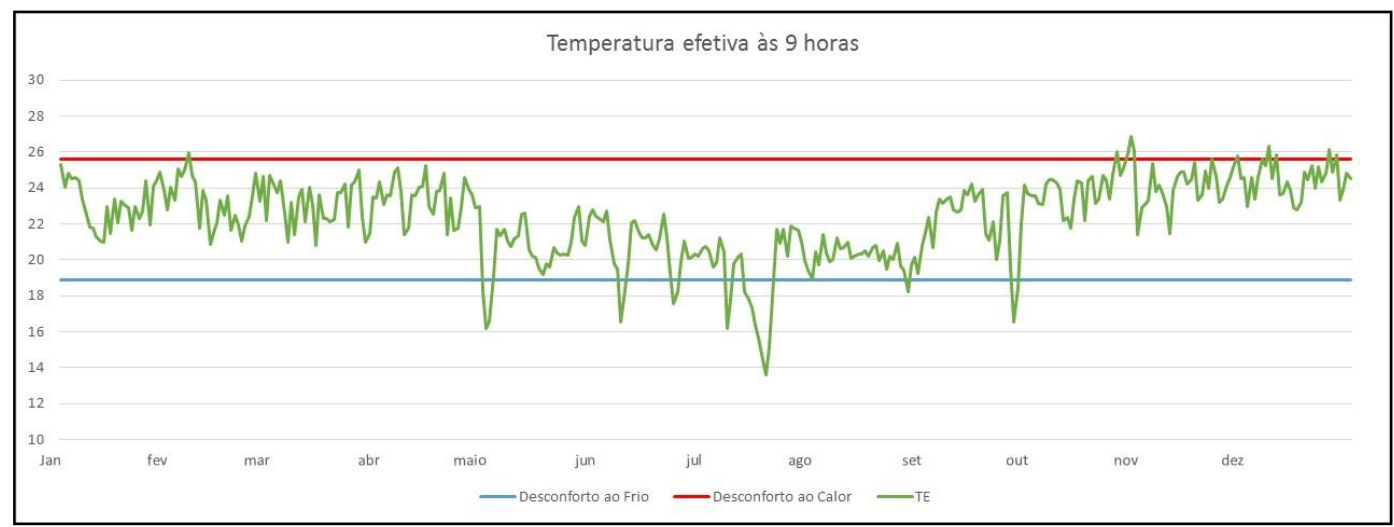

Figura 8 - Temperatura efetiva em área menos urbanizada (P2) às 9 horas / Fonte: Laboratório de Climatologia. UFG/Regional Jataí / Organização: ROCHA, J. R. R (2013)

O mês de julho apresentou as menores temperaturas efetivas, tanto no P2 como no P4, como notamos na carta sinótica de superfície do dia 19/07, em que ocorreu a menor temperatura efetiva. Às 3 horas, existia um sistema frontal estacionário desde o extremo sul do Acre até o sul do Espirito Santo e segue como frio pelo Atlântico, até uma área por volta 32S/34W, e às 9 horas esse sistema frontal enfraqueceu no continente e ficou estacionário entre o leste de MG e o ES (Figura 9), (INPE-CPETEC-GPT). Assim, percebe-se que esse sistema frontal fez com que as temperaturas mínimas diminuíssem, ocasionando desconforto ao frio para a população. 


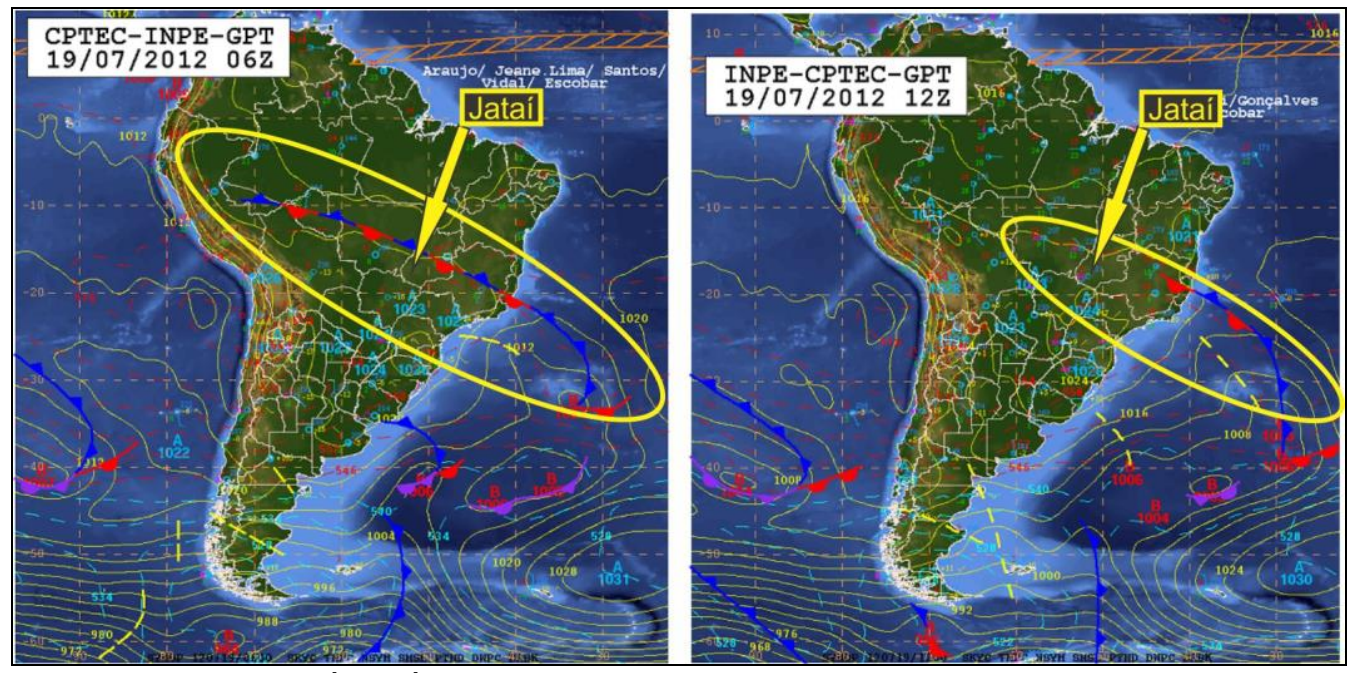

Figura 9 - Carta sinótica às 3 e 9 horas do dia 19/07/2012 / Fonte: CEPETEC (2012)

\subsection{2 - Temperatura efetiva as 15 horas}

No horário das 15 horas, a temperatura efetiva máxima foi de $31,3^{\circ} \mathrm{C}$, em outubro (dia 30 ), com desconforto em relação ao calor, e a menor em abril, com $18,9^{\circ} \mathrm{C}$ (dia 30), com desconforto em relação ao frio (Figura 10). Na localidade P4, tiveram 2 dias de temperaturas de desconforto térmico em relação ao frio (30/04 e 08/06) nos meses de outono e inverno, sendo em abril, no dia $30\left(18,3^{\circ} \mathrm{C}\right)$, e junho, no dia 8 $\left(18,4^{\circ} \mathrm{C}\right)$.

Neste horário, as temperaturas efetivas prevaleceram como desconfortáveis em relação ao calor, com 255 dias de desconforto. Assim, apenas 108 dias tiveram conforto e 2 dias com desconforto em relação ao frio.

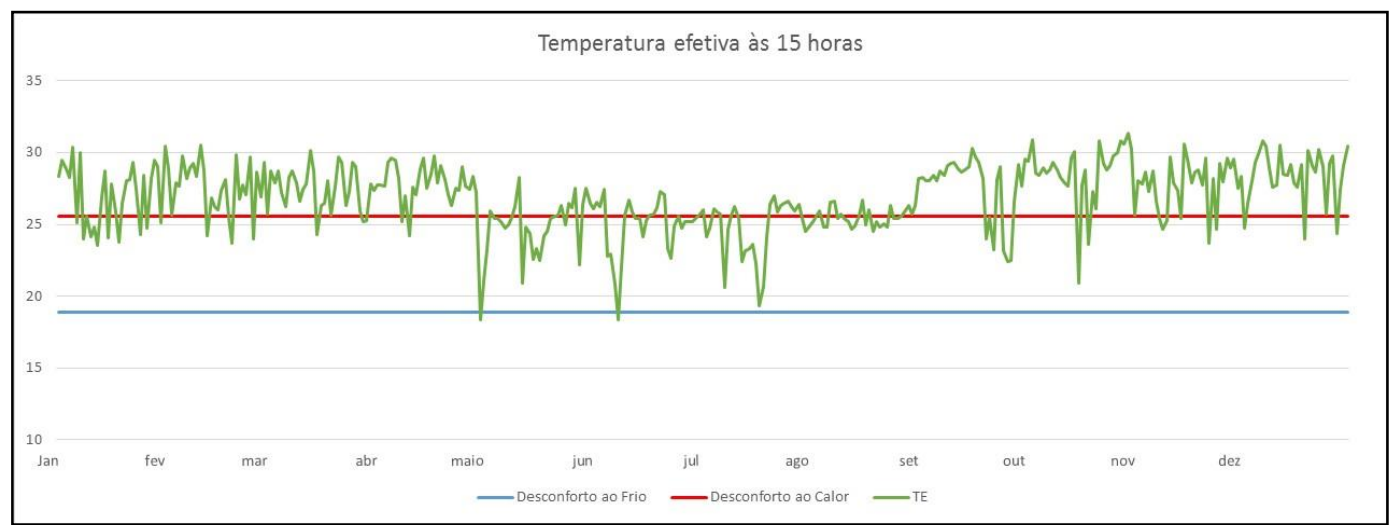

Figura 10 - Temperaturas efetivas em área mais urbanizada (P4) às 15 horas / Fonte: Laboratório de Climatologia. UFG/Regional Jataí / Organização: ROCHA, J. R. R (2013) 
Na localidade $\mathrm{P} 2$, às 15 horas, a amplitude da temperatura efetiva foi de $11,8^{\circ} \mathrm{C}$, sendo que a maior temperatura efetiva $\left(29,4^{\circ} \mathrm{C}\right)$ ocorreu no mês de outubro (dia 30) e a menor temperatura efetiva em abril, com $17,6^{\circ} \mathrm{C}$. Assim, foram 3 dias de desconforto ao frio, 171 dias de desconforto ao calor e 191 dias de conforto térmico (Figura 11).

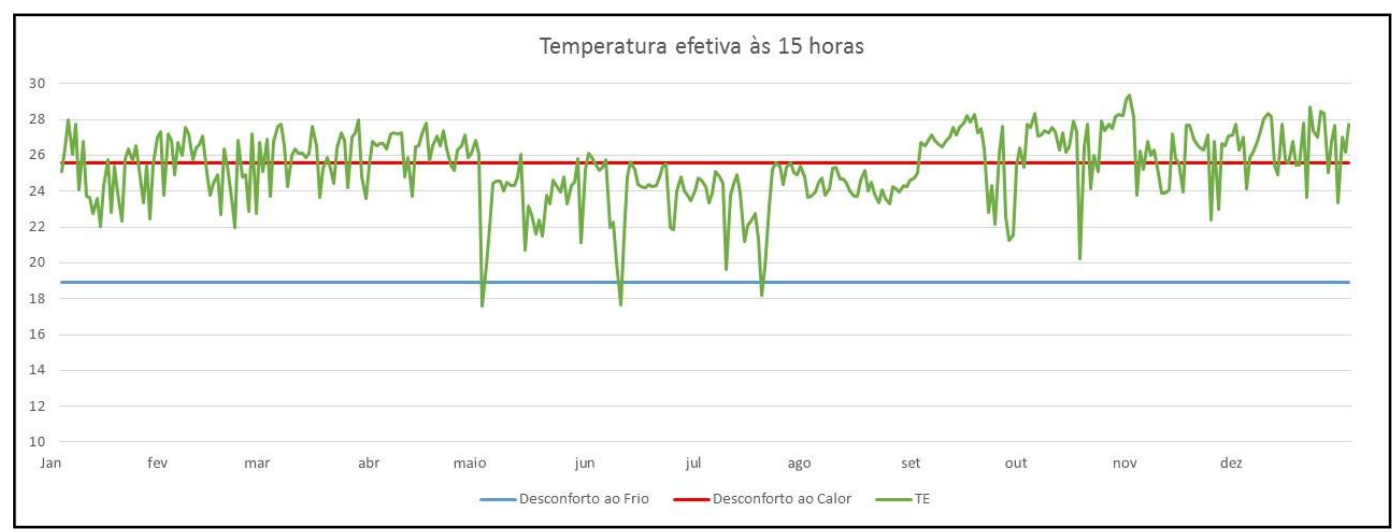

Figura 11 - Temperatura efetiva em área menos urbanizada (P2) às 15 horas / Fonte: Laboratório de Climatologia. UFG /Regional Jataí / Organização: ROCHA, J. R. R (2013)

Dessa forma, pode-se observar que, no horário das 15 horas, a área mais urbanizada (P4), no centro da cidade, apresentou temperaturas efetivas mais elevadas em relação à área menos urbanizada (P2) e com maior arborização.

De acordo com as cartas sinóticas do INPE-CPETEC-GPT, no dia 1/05 teve a presença de frente estacionária com característica fria a leste de 50W e ao sul de 20S, sendo que no dia anterior, 30/04 (carta não disponibilizada no horário do dia), teve a menor temperatura efetiva, tendo desconforto em relação ao frio. Já no dia 18/07, há atuação do ramo frio de uma onda frontal desde o sul do Amazonas até Minas Gerais, abrangendo a área de estudo. Desta forma, percebe-se nas cartas dos dias 01/05, 08/06 e 18/07 uma frente estacionária, que faz com que as temperaturas diminuam, ocasionando temperaturas efetivas com desconforto em relação ao frio. Já no dia 19/07, esse sistema frontal enfraqueceu no continente, tomando ramo estacionário entre o norte do ES e sul da BA; assim, as temperaturas voltaram a se elevar a partir do mês de agosto, tendo temperaturas efetivas mais altas, ocasionando desconforto em relação ao calor, nas duas localidades de análise (Figura 12). 

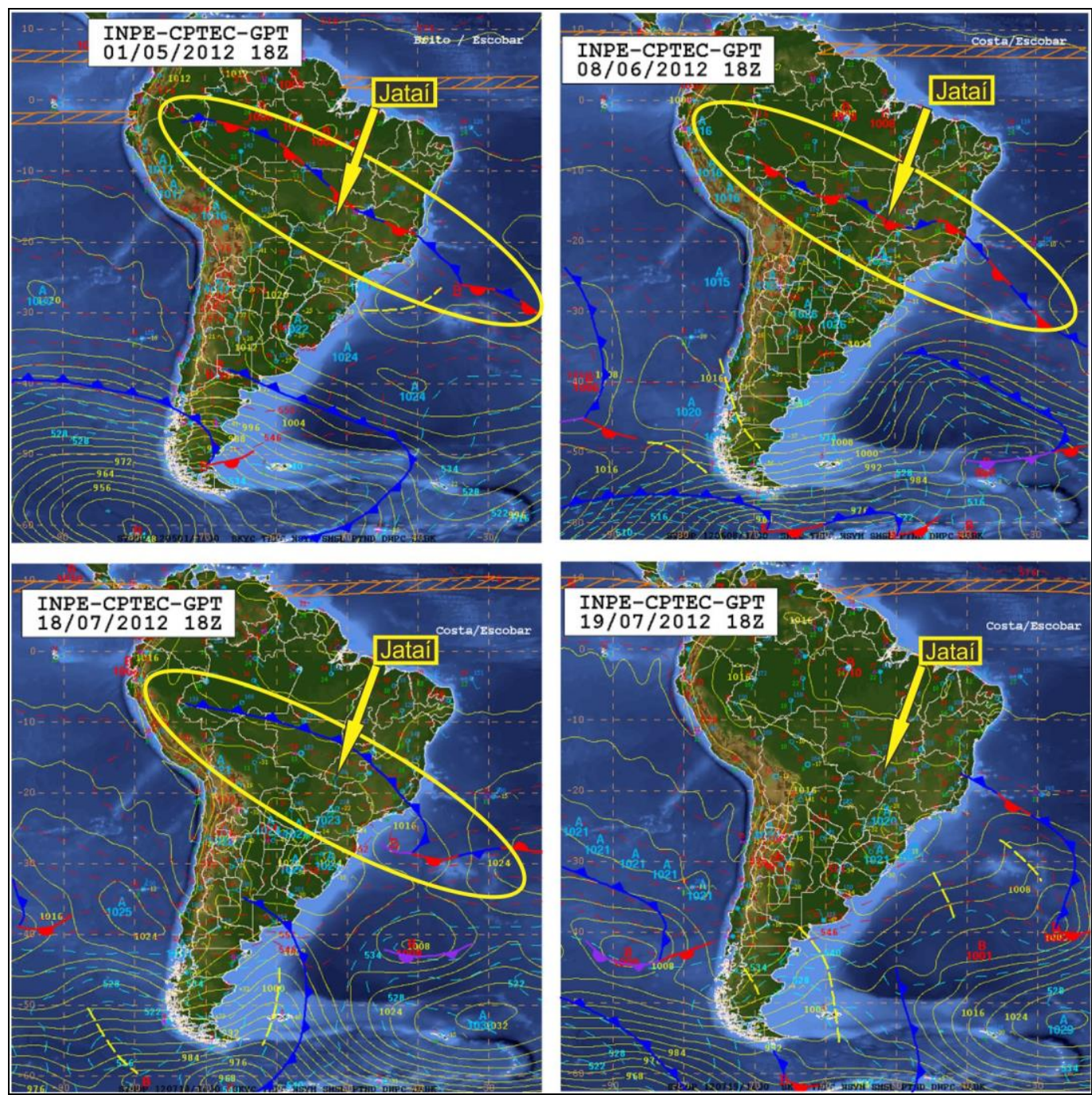

Figura 12 - Cartas sinóticas no horário das 15 horas nos dias 01/05, 08/06, 18/07 e 19/07/2012 / Fonte: CPETEC (2012)

\subsection{3 - Temperatura efetiva às 21 horas}

Às 21 horas, as temperaturas efetivas na localidade P4 oscilaram de 13,8 a $25,7^{\circ} \mathrm{C}$, em que a menor temperatura é considerada como desconforto ao frio e a maior situa-se na zona de conforto térmico (Figura 13). A menor temperatura efetiva ocorreu no dia 18 de julho, no inverno, em que Mariano (2005) coloca que, devido à continentalidade, baixa umidade do ar e atuação frequente do anticiclone Polar, são comuns dias muitos frios (abaixo de $10,0^{\circ} \mathrm{C}$ ), sobretudo em junho e julho. Desta forma, a localidade teve 25 dias de temperaturas efetivas em relação a 
desconforto ao frio e 1 dia de desconforto em relação ao calor (29 novembro).

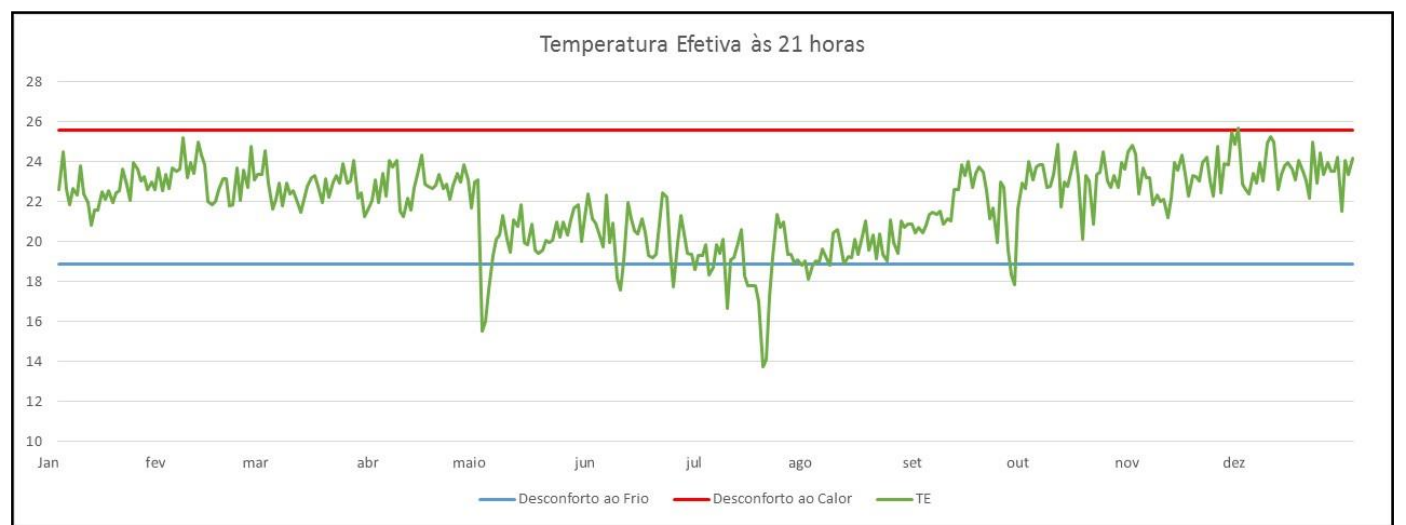

Figura 13 - Temperatura efetiva em área menos urbanizada (P4) às 21 horas / Fonte: Laboratório de Climatologia. UFG/Regional Jataí / Organização: ROCHA, J. R. R (2013)

No horário das 21 horas, a localidade $\mathrm{P} 2$ apresentou temperaturas efetivas para o desconforto ao calor no dia 30 de outubro $\left(26,1^{\circ} \mathrm{C}\right)$. Já nos meses de abril, maio, junho, julho e setembro, ocorreram temperaturas de desconforto ao frio, sendo que o mês de julho apresentou a menor temperatura, $14,9^{\circ} \mathrm{C}$ (dia 18). Desta forma, neste horário, o ano teve 14 dias de desconforto ao frio e 1 dia de desconforto em relação ao calor (Figura 14).

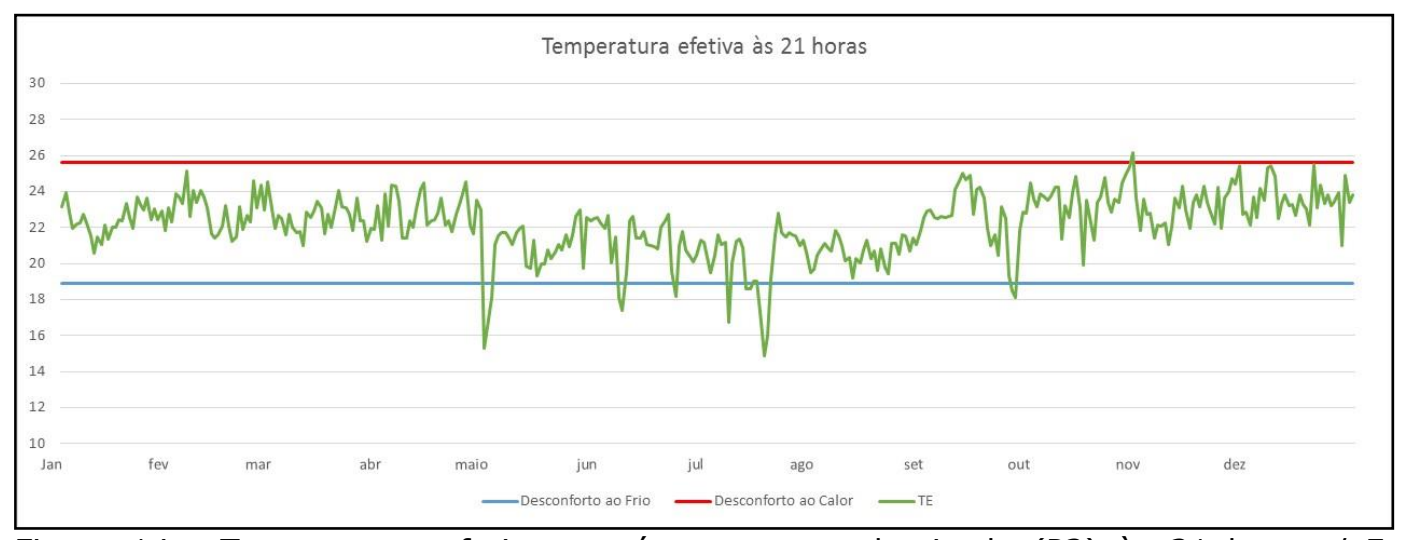

Figura 14 - Temperatura efetiva em área menos urbanizada (P2) às 21 horas / Fonte: Laboratório de Climatologia. UFG/Regional Jataí / Organização: ROCHA, J. R. R (2013)

\section{CONCLUSÕES}

Os estudos sobre o clima urbano são realizados, em sua maioria, em 
cidades de grande porte. No entanto, mesmo sendo considerada uma cidade de pequeno porte, Jataí tem condicionantes capazes de criar vários microclimas dentro de sua malha urbana, influenciando o modo de vida da população residente. Evidentemente que as diferenças térmicas e higrométricas verificada em Jataí não se comparam com as registradas nas metrópoles; porém, registram diferenças térmicas e higrométricas significativas. No entanto, quando diagnosticado o problema, a resolução nas cidades pequenas é mais fácil, devido à sua dinâmica urbana e sua escala de trabalho.

Diante dos resultados, conclui-se que:

a) Em relação às temperaturas máximas absolutas, os pontos que apresentaram a maior temperatura foram os pontos P4 e P1 em relação aos demais pontos, sendo que as características das localidades contribuem para o aquecimento, sendo o P4 localizado no centro da cidade, com fluxo de veículos e pessoas, área comercial, e o P1 num residencial habitacional (Conjunto Residencial Mauro Antônio Bento), tendo casas próximas, com pouca arborização;

b) As temperaturas mínimas absolutas são encontradas no P7 e P2, sendo que a localização influencia os valores, onde O P7 fica localizado em uma área sendo considerada rural (INMET) e o P2 com pouca construção de casas e pavimentação e com arborização;

c) Em relação à temperatura efetiva às 9 horas, conclui-se que na maioria dos dias esteve entre a zona de conforto térmico $(18,9$ a $\left.25,6^{\circ} \mathrm{C}\right)$, sendo que na estação do inverno ocorreu desconforto ao frio (menor que $18,9^{\circ} \mathrm{C}$ );

d) Às 15 horas, em todos os meses, as temperaturas efetivas prevaleceram como desconfortáveis em relação ao calor (acima de $\left.25,6^{\circ} \mathrm{C}\right)$;

e) Às 21 horas, as temperaturas prevalecem na zona de conforto, sendo registrados alguns dias (P4, 25 e P2, 14 dias) de temperaturas efetivas com desconforto em relação ao frio e 1 dia de desconforto em relação ao calor nas duas localidades;

f) As maiores temperaturas máximas absolutas e desconforto térmico ao calor foram encontradas na localidade P4, devido à sua localização, sendo paralela à avenida principal da cidade (Av. Goiás), com intenso fluxo de veículos e pessoas, centro comercial e agências bancárias, além de barracões de armazenamento próximos com material de zinco; 
g) As menores temperaturas mínimas absolutas e desconforto térmico ao frio também foram na localidade P4, sendo 97 dias de desconforto às 9 horas, 15 dias às 15 horas e 25 dias às 21 horas, enquanto que a localidade P2 apresentou valores menores, 20, 3 e 14 dias ( 9,15 e 21 horas respectivamente).

\section{AGRADECIMENTOS}

Agradecimentos: Coordenação de Aperfeiçoamento de Pessoal de Nível Superior (Capes), pelo apoio financeiro (bolsa de mestrado); ao CNPq $\mathrm{n}$. 477869/2012-2 (Apoio financeiro em capital e custeio); às pessoas voluntárias das localidades por permitirem a instalação dos aparelhos, tanto em locais públicos quanto particulares, assim contribuindo para o desenvolvimento do presente trabalho e a dissertação de mestrado.

\section{REFERÊNCIAS}

ABDALA V. Homicídios crescem 52,2\% nas cidades pequenas em dez anos. Agência Brasil. Empresa Brasil de comunicação. 20 dez. 2013. Disponível em: <http://memoria.ebc.com.br/agenciabrasil/noticia/2013-12-20/homicidio screscem-522-nas-cidades-pequenas-em-dez-anos-diz-ipea>. Acesso em 14 abr. 2014.

AMORIM. M. C. de C. T. Climatologia e gestão do espaço urbano. Revista Mercator - número especial, 2010: dez. Disponível em: < http://www.mercator.ufc.br/index.php/mercator/article/viewFile/534/299>.

Acesso em: 27 ago. 2013.

ANDRADE, Henrique. O clima urbano - natureza, escalas de análise e aplicabilidade. Finisterra - Revista Portuguesa de Geografia. XL (80). Lisboa, 2005. Disponível em: <http://www.ceg.ul.pt/finisterra/numeros/200580/80_05.pdf >. Acesso em: 29 jun. 2013.

ANUNCIAÇÃO, V.S., SANT'ANNA NETO, J.L., O Clima Urbano da Cidade de Campo Grande - MS. p.61-87. In. SANT'ANNA NETO, J.L. (Org.) Os Climas das Cidades Brasileiras. Presidente Prudente, 2002. p. 61-87.

BARBOSA, H. P. AMORIM, M. C. de C. T. Clima urbano em Presidente Prudente/SP: diferenças térmicas e higrométricas urbano/rural em episódios de outono. Revista Geonorte, Amazonas, Edição Especial 2, V.2, N.5, p. 220 - 232, 2012.

Disponível em:

http://www.revistageonorte.ufam.edu.br/attachments/013_(CLIMA\%20URBANO\% 20EM\%20PRESIDENTE\%20PRUDENTESP\%20DIFEREN\%C3\%87AS\%20T\%C3\%89 RMICAS\%20E\%20HIGROM\%C3\%89TRICAS\%20URBANORURAL\%20EM\%20EPIS\% C3\%93DIOS\%20DE\%200UTONO).pdf>. Acesso em: 13 jun. 2013. 
BARDUCO, G.L.; GALVANI, E. Análise do conforto e desconforto térmico em transportes públicos a linha de ônibus 107- T (Cidade Universitária Metrô Tucuruvi): um estudo de caso. In: Simpósio Brasileiro de Geografia Física Aplicada, 15, 2013, Vitória, ES. Uso e ocupação da terra e as mudanças das paisagens. Vitória, ES: Universidade Federal do Espírito Santo - UFES, 2013. v. 15. p. 57-65.

BASANE, A. C.; SILVA, R. F.; MIRANDA, Y. C.; BALDO, M. C. A influência do clima urbano em cidades de pequeno porte: uma revisão teórica. In. Simpósio de Estudos Urbanos: Desenvolvimento Regional e Dinâmica Ambiental, 1, 2011, Paraná. Anais eletrônicos... Fecilcam: Campo Mourão/PR, 2011. Disponivel em: <http://www.mauroparolin.pro.br/seurb/Trabalhos/EIXO_12_

CLIMA_URBANO_3_ARTIGOS/BASANE_A_INFLUENCIA_DO_CLIMA_URBANO_EM_ CIDADES_DE_PEQUENO_PORTE_UMA_REVISAO_TEORICA.pdf $>$. Acesso em 22 out. 2013.

FIALHO. E. S.; SOUZA. J. J. L. L. de. Utilização do clima no planejamento como reflexo das condições ambientais nos centros urbanos. Revista ACTA Geográfica, ANO I, n. 2, jul./dez. de 2007. p.29-41. Disponível em: < http://revista.ufrr.br/index.php/actageo/article/download/175/352>. Acesso em 26 jun. 2013.

IBGE. Cidades. 2010 Disponível em: <http://cidades.ibge.gov.br/xtras/ perfil.php?codmun=521190 > . Acesso em: ago. 2013.

LIMA, Lorena Cavalcante. ZANELLA, Maria Elisa. A climatologia aplicada ao planejamento urbano e ambiental de Aquiraz/CE-BR. Revista Geográfica de América Central, Costa Rica, 2011. Disponível em:< http://www.revistas.una.ac.cr/index.php/geografica/article/download/2633/2516 >. Acesso em: 22 mai. 2013.

LOMBARDO, M. A. Ilha de calor nas metrópoles: o exemplo de São Paulo. São Paulo: Editora Hucitec, 1985. 244p.

MARIANO, Z. de F. A importância da variável climática na produtividade da soja no sudoeste de Goiás. 2005. 251 f. Tese (Doutorado em geografia) UNESP - Campus de Rio Claro, Rio Claro: 2005.

MENDONÇA, Francisco. Clima e criminalidade: ensaio analítico da correlação entre a temperatura do ar e a incidência de criminalidade urbana. Curitiba. UFPR, 2001.

MONTEIRO, C. A. de. F. Teoria e clima urbano. 1976. 181 f. Tese. (Apresentada ao concurso de livre- docência junto ao Departamento de Geografia) - Faculdade de Filosofia, Letras e Ciências Humanas da Universidade de São Paulo, São Paulo, 1976.

Organização Mundial de Saúde. HEAT STRESS. IN. Atlas of health and climate. 2012. p. 404 - $43 . \quad$ Disponível em: 
<http://apps.who.int/iris/bitstream/10665/76224/4/9789241564526_section_3_e ng.pdf>. Acesso em: 15 jun. 2013.

PEREIRA, I.; ALVES, T.; PINHEIRO, R.; ASSIS, E. Metodologia de tratamento de dados climáticos para inserção em softwares de simulação energética de edifícios. In. Conferência latino-americana de construção sustentável, 1 , e Encontro Nacional de tecnologia do ambiente construído, 10. São Paulo, 2004. Disponível em: <http://www.arquitetura.ufmg.br/labcon/download.php?dir=arquivos/\&file=PAP1 057d.pdf>. Acesso em: 15 ago. 2013.

ROSSATO, P. S. O sistema termodinâmico do clima urbano de Nova Palma, RS: contribuição ao clima urbano de cidades pequenas. 2010. $121 \mathrm{f}$. Dissertação (Mestrado - Programa de Pós - Graduação em Geografia e Geociências - Área de concentração Sociedade e Meio Ambiente) - Universidade Federal de Santa Maria/UFSM, RS, Santa Maria, 2010.

SANTOS, A. M. S. P; COSTA, L. S., ANDRADE, T. A. Federalismo no Brasil: análise da descentralização financeira da perspectiva das cidades médias. IN: ANDRADE, T. A., SERRA, R. V. (Org.) Cidades médias brasileiras. Rio de Janeiro: IPEA, 2001, p. 295-335.

SILVA, M. R. Encontros e desencontros: estudo do espaço urbano de Jataí-GO. Dissertação (mestrado) - Universidade Federal de Goiás, Instituto de Estudos Sócio-Ambientais, Goiânia, 2005.

SILVA, Silvando Carlos da. SANTANA. Neiva Maria Pio de. PELEGRINI, José Cardoso. Caracterização climática do Estado de Goiás. Goiânia, 2006. Disponível em: < http://www.sieg.go.gov.br/downloads/Livro_Clima.pdf>. Acesso em: 28 jun. 2013

VICENTE, A. K. et al. Conforto térmico em Presidente Prudente-SP. In: SANT' ANNA NETO, J. L. (Org.). Os climas das cidades brasileiras. Presidente Prudente: 2002, p.197 - 227. 